\title{
INTERSUBJETIVIDADE NA LINGUAGEM: A ESPADA DE DÂMOCLES EM PROGRAMA DE GOVERNO
}

\section{INTERSUBJECTIVITY IN LANGUAGE: THE DAMOCLES SWORD IN GOVERNMENT PROGRAM}

\author{
Realdo José Sorato* \\ Maria Marta Furlanetto***
}

\begin{abstract}
Resumo: Este trabalho objetiva discorrer sobre alguns enunciados expostos no Programa de Governo de Jair Messias Bolsonaro, postulante, em 2018, ao cargo de Presidente da República do Brasil, associando análise discursiva a aportes das ciências sociais. Ao apontar o que neles se apresenta, tomado como aparência, e o que pode ser compreendido pela análise, visto como essência, identifica um horizonte opacificado, pela forma de materialização dos enunciados em sua produção - organização linguística, escolhas estilísticas, silenciamento. Ao trazer uma proposta permeada de valores explicitados, ao mesmo tempo marcando-se em oposição a outro grupo político eleito como o mal encarnado - explicitamente ou de modo genérico - o Programa remete a um posicionamento politicamente ambíguo, mas, atraente, pelo caráter que apresenta de liderança capaz de salvar a Pátria, com apelo sintetizado no lema Ordem e progresso.
\end{abstract}

Palavras-chave: discursividade; campanha política; plano de governo.

Abstract: This work aims to discuss some of the statements exposed in the Government Program of Jair Messias Bolsonaro, postulant, in 2018, to the position of President of the Republic of Brazil, associating discursive analysis with contributions from the social sciences. By pointing out what appears in them, taken as appearance, and what can be understood by analysis, seen as essence, it identifies an opacified horizon, through the form of materialization of the statements in their production linguistic organization, stylistic choices, silencing. By bringing a proposal permeated with explicit values, at the same time marking itself in opposition to another political group elected as evil incarnate - explicitly or in a generically -, the Program refers to a politically ambiguous position, but, attractive, for the character that presents

\footnotetext{
"Doutor em Ciências da Linguagem na Universidade do Sul de Santa Catarina - UNISUL, Centro de Pós-graduação, campus Tubarão. ORCID: https://orcid.org/0000-0002-2458-5619. E-mail: realdojs@gmail.com.

"** Doutora em Linguística Aplicada pela Universidade de Paris VIII (Vincennes, França). Docente aposentada da Universidade Federal de Santa Catarina. Docente da Universidade do Sul de Santa Catarina (UNISUL) no período $2000-2020$. Editora Honorária da revista Linguagem em (Dis)curso, do Programa de Pós-graduação em Ciências da Linguagem da Unisul. Orcid: https://orcid.org/0000-0002-0298-765X. E-mail: mmartafurlanetto@gmail.com.
} 
leadership capable of saving the Nation, with an appeal summarized in the motto Order and progress.

KeYwords: discourse; political campaign; government plan.

\section{INTRODUÇÃo}

O mundo que nos cerca é percebido pelo sentido da visão, através dos espectros de luz que todos os objetos produzem. Desta forma, o que conseguimos ver corresponde a uma pequena fração ${ }^{1}$ do que realmente se poderia ver. Fato similar ocorre com os sons que conseguimos ouvir, pois nossa capacidade auditiva é restrita a uma pequena faixa de vibrações, entre $20 \mathrm{e}$ 20.000 hertz $(\mathrm{Hz})^{2}$. Portanto, o mundo que vemos e ouvimos, sem próteses auxiliares, dista do que poderia ser visto e ouvido, ou seja, a aparência do mundo (o que percebemos) difere do que vamos chamar sua essência (em sentido amplo, como fundamento). Explicamos adiante o sentido que atribuímos a este par de categorias. Nossa capacidade de desenvolver dispositivos que permitem transpor limites nos leva a perceber que somos poderosos (cognitivamente) e, ao mesmo tempo, muito limitados (fisicamente).

Com base neste pressuposto, e o uso de noções discursivas e de ciências sociais, objetivamos discorrer sobre alguns enunciados do Programa de Governo de Jair Messias Bolsonaro 3 , como postulante ao cargo de Presidente da República nas eleições de 2018. Mostramos interpretações que podem ser tecidas acerca dos enunciados, e que eles surgem como pontos em uma rede extensa de memória discursiva e de outros enunciados que com eles convivem, em determinado momento histórico-social.

Não se trata de emitir juízos de valor sobre o conteúdo dos enunciados, mas mostrar que, entre o que neles se apresenta como evidência ou naturalidade (aparência) e o que poderiam representar (essência), pode haver um horizonte que nos escapa, num primeiro momento. Esses pontos de fuga podem ser eventualmente facilitados pela forma de materialização em sua produção (organização linguística, escolhas estilísticas, silenciamentos etc.).

Para exemplificar essa proliferação de leituras (percepção não linear) e a heterogeneidade da relação leitor/sentidos, Orlandi (2008) descreve experiência pessoal com um trabalho estético - no caso, uma fotografia. Observa uma representação plana, aparentemente sem espessura, e nota que a percepção viaja, produzindo efeitos múltiplos na linguagem, como a polifonia: pontos de fuga, de entrada para o olhar, marcando a historicidade (cf. ORLANDI, 2008,

\footnotetext{
${ }^{1}$ Ilustrações podem ser vistas em: https://mundoeducacao.bol.uol.com.br/fisica/luz-visivel.htm.

${ }^{2}$ Informações complementares disponíveis em: https://www.em.com.br/app/noticia/especiais/educacao/enem/2015/11/11/ noticia-especial-enem,706844/ondas-sonoras-e-a-capacidade-do-homem-em-emitir-sons.

${ }^{3}$ Este texto foi iniciado e desenvolvido em sua maior parte durante a campanha presidencial, e finalizado após a eleição, em segundo turno, do candidato.
} 
p. 113-115). E conclui, quanto à leitura: "A unidade do texto, para o leitor, é 'fugaz'." (ORLANDI, 2008, p. 114): há uma intervenção, uma coprodução, não apenas a leitura plana, domesticada.

A noção de discurso que perspectivamos, retomando algumas características de correntes teóricas contemporâneas, tem em seu entorno noções que conduzem a sua especificidade: frase, enunciado, enunciação - diferenciando-se teoricamente de todas elas. Se as línguas têm em sua base uma estrutura e um modo de organização, as sequências linguísticas se articulam e formam enunciados, ou seja, são enunciadas em contexto cultural, social e histórico, produzindo, de modo coletivo, tipos específicos, com funcionamento próprio (e não apenas funções, tais como as sintáticas e as semânticas): discurso científico, discurso político, feminista, religioso etc. Esclarecemos, com isso, que, se podemos observar enunciados e textos produzidos por este ou aquele autor, discurso não é produção individual, mas coletiva, de caráter social e cultural - com sua memória coletiva, com seu imaginário. É um objeto de pesquisa, não imediatamente aparente, mas a buscar, a estudar a partir do que é textualizado (verbalmente ou não). Não fosse assim, não faria sentido a existência de estudos científicos em análise do/de discurso.

Em 2018, os postulantes à presidência da República socializaram ao público seus planos de governo. Um dos mais relevantes, por se tratar de um político cujas ideias arregimentaram muitos adeptos, foi o de Jair Messias Bolsonaro. Nele, materializaram-se suas principais ideias de governo, conceitos e valores. Eles permitem observar que sentidos foram exaltados, apagados ou silenciados (cf. ORLANDI, 2001), bem como possíveis vetores: planejamento, intuito de indução, direcionamento ou cooptação de seguidores ideologicamente alinhados com essas ideias e valores. É com o intuito de analisar estes deslizamentos (intencionais ou não) que se desenvolve este artigo, com vistas a possibilitar novas leituras.

\section{Mitos SociaIs}

Neste estudo, redimensionamos em termos discursivos o par aparência/essência que nos serve de inspiração. Assumimos que a aparência corresponde ao que a superfície do que é enunciado mostra em seu aspecto de literalidade, ou melhor, de sua possibilidade de interpretação pelo dito ou exposto, sem a armadura teórica que permita dessuperficializar o fio discursivo; a essência implica a historicidade que se pretende buscar como efeito de leitura compreensiva, voltada para o que é silenciado, para a reflexão sobre o funcionamento discursivo, a partir do caráter opaco da linguagem, em que se instala o político, o ideológico, o simbólico. Assim, não tratamos essência como o próprio real (ou verdadeiro); o real não se atinge. Teorias, de todo modo, não revelam, em si, verdades: mostram efeitos de perspectiva, especialmente tratando-se de sociedade e valores humanos.

A linguagem humana tem a capacidade de ser extremamente versátil no tratamento da realidade. Nesse processo, há incongruência entre a essência e a aparência, não mero reflexo. 
Do ponto de vista psicanalítico podemos dizer, com Lacan (1988), que a relação dos humanos com o mundo em que vivem tem um preço: "[...] a realidade é marcada de saída pela aniquilação simbólica" (LACAN, 1988, p. 171, grifo no original). Ou seja: se existe uma realidade anterior à simbolização, mítica ou não, o símbolo a aniquila - no sentido de que o real é inalcançável: a linguagem não é natural, é criada culturalmente, e uma característica singular é a possibilidade de fazer referência a coisas que existem apenas em nossas mentes. Por meio das diversas formas de materialização linguística, tentamos representar e criar um elo com os outros. Nas palavras de Paveau (2013, p. 23):

Toda a reflexão sobre os (pré)dados coletivos que permitem a comunicação entre homens e a percepção do mundo é, sem dúvida, uma tentativa de responder a uma questão muito simples, embora fundamental: se há alguma coisa que acontece entre mim, o mundo e os outros, do que se trata e como isso funciona?

Entramos no mundo humano da intersubjetividade: produzimos inter-relações para todos os fins em nossas comunidades e aprendemos uns com os outros. Enunciamos nossos projetos como resultado de intencionalidade. Não nos referimos aqui especificamente a intenções de caráter psicológico, ou seja, de consciência plena em termos de vontade e querer. Como destaca Kleinman (2014, p. 107): “[...] a intencionalidade não se relaciona à intenção de alguém para fazer ou não fazer algo, mas, em vez disso, é a capacidade que temos de pensar em relação a algo". Trata-se, portanto, de direcionalidade - movimento de sentido.

Para sobreviver em um grupo, a cooperação, em suas diversas formas, e a linguagem surgem como fatores preponderantes: por meio delas, conseguimos "existir" no grupo, compartilhando conceitos, mitos, lendas, deuses, religiões, política, valores - construindo uma memória histórica agregadora, coletiva, simbólica, que manifestaria sua essência - para além de uma aparência material composta por pessoas, edificações, ruas, carros, bibliotecas etc.

Neste sentido, Harari menciona (2017, p. 33):

Podemos tecer mitos compartilhados, tais como a história bíblica da criação, os mitos do Tempo do sonho dos aborígenes australianos e os mitos nacionalistas dos Estados modernos. Tais mitos dão aos sapiens a capacidade sem precedentes de cooperar de modo versátil em grande número.

Envolvendo toda comunidade, existe um "ente contratual" (também um mito) que se mostra sob duas formas: uma juridicamente estabelecida, com direcionamento legal, que pode ser acessado pelos sujeitos pragmáticos; e outra subjetivamente estabelecida, com valores, crenças, relações, manifestados em práticas compartilhadas como costume coletivo, como tradição - incluindo uma memória coletiva - como o sociólogo Maurice Halbwachs (1990) a concebe na 
obra A memória coletiva ${ }^{4}$ que pode permanecer adormecida por algum tempo, mas emerge em determinadas situações. Como expressa Halbwachs (1990, p. 92-93):

[...] em torno de alguns objetos nosso pensamento se encontra com os dos outros; é em todo o caso, no espaço que imagino a existência sensível daqueles com quem, pela voz ou pelos gestos, relaciono-me a todo momento. Assim, produzir-se-iam cortes ao mesmo tempo em minha duração e na deles, mas que tendem a estender-se às durações ou às consciências dos outros homens, de todos aqueles que se encontram no universo.

Essa memória aflora quando somos expostos a situações não rotineiras, tal como uma eleição para presidente, surgindo, espontaneamente, grupos com posicionamentos políticos divergentes. Orlandi (2012, p. 3), em entrevista concedida ao G1, Portal de notícias do Grupo Globo, explica: "O político está no fato de que, como nossa sociedade é dividida, há uma divisão nos sentidos, eles não significam a mesma coisa para todos, mas, sim, na diferença" - diferença que, de repente, emerge de algum ponto e começa a tomar forma e criar feudos. Como reflete Halbwachs (1990, p. 40): “Uma 'corrente de pensamento' social é ordinariamente tão invisível como a atmosfera que respiramos. Só reconhecemos sua existência, na vida normal, quando a ela resistimos".

No sentido mais corrente, na Análise de Discurso originada na França, na década de 1960, a memória se instala como interdiscurso, manancial de enunciados e sentidos já formulados e interiorizados, que adquirem caráter inconsciente e possibilitam as formulações. Uma formulação pode ser entendida como "a atualização, a textualização da memória" (ORLANDI, 2001, p. 16). Mas não é tudo: a memória também funciona vinculada às possibilidades de arquivamento institucional; é o que se faz quando se busca algo ou se faz pesquisa. O tratamento conceptual da memória vai se refinando na Análise de Discurso e não permanece amarrado ao funcionamento inconsciente - que é importante, sem dúvida, e tem um papel marcante na análise discursiva. Em Papel da memória, Pêcheux (1999[1983]) vê a noção de memória discursiva num jogo de repetição e regularização, restabelecendo elementos implícitos necessários à leitura, mas, ao mesmo tempo, com deslocamentos e retomadas, sob o investimento de um acontecimento discursivo.

Ainda que sob a dominância de uma política que atua sobre uma grande comunidade - o povo de uma nação - essa mesma comunidade se estilhaça em inúmeras comunidades menores que, mesmo mantendo laços entre si (regulares ou esporádicos), têm características que marcam sua singularidade.

\footnotetext{
${ }^{4}$ Michel Pêcheux, em um de seus últimos trabalhos, de 1983, se aproxima desse conceito, remetendo aos historiadores das mentalidades: "a memória deve ser referida [...] a um conjunto complexo, preexistente e exterior ao organismo, constituído por séries de tecidos de índices legiveis, constituindo um corpo sócio-histórico de traços” (PÊCHEUX, 1990, p. 286, grifo do autor, tradução nossa).
} 
Por força de diferenças, tal como a que se designa economicamente como classe- $\mathrm{A}, \mathrm{B}$ ou C - urbana ou campesina, partilha-se de grupos também por valores menos pragmáticos, formando uma cultura prismática de saberes e conhecimentos, desde aqueles de caráter mais profundamente religioso até os considerados de caráter científico estrito.

Admitindo-se essas duas orientações - da vida em seu aspecto pragmático, orientada político-juridicamente por normas legitimadas, e da vida orientada por opções associadas a experiências particulares - é nesse segundo plano que certas escolhas - no caso em pauta, de candidato para um cargo político, como alternativa de forma de poder - são influenciadas pelos fatores que modelam uma comunidade: experiências pessoais enraizadas ideologicamente, criando suscetibilidades, transferindo poderes e recriando mitos. Não se trata de um poder relacionado à força (somente); como escreve Foucault (1995, p. 243), "[...] ele não é, em si mesmo, renúncia a uma liberdade, transferência de direito, poder de todos e de cada um delegado a alguns [...]; a relação de poder pode ser o efeito de um consentimento anterior ou permanente; ela não é, em sua própria natureza, a manifestação de um consenso". Ela é "um modo de ação de alguns sobre os outros" (FOUCAULT, 1995, p. 242).

\section{IMAGINÁRIO E MITO}

Como o Homo sapiens, pergunta Harari (2017, p. 35), conseguiu fundar "cidades com dezenas de milhares de habitantes e impérios que governam centenas de milhões?” A resposta é: "O segredo foi provavelmente o surgimento da ficção. Um grande número de estranhos pode cooperar de maneira eficaz se acreditar nos mesmos mitos" (HARARI, 2017, p. 36, grifo nosso). Trata-se, portanto, de funcionamento imaginário, e não, meramente, de efeito natural. Estados se baseiam em mitos nacionais: na Igreja há santos, e na vida nacional, heróis.

Reteremos duas noções: a de imaginário - de que já disseminamos aspectos acima - e a de mito, para esclarecer como as entendemos neste contexto.

Maffesoli (2001), no contexto da sociologia compreensiva, esclarece a noção de imaginário no campo das ciências humanas, lembrando, primeiramente, não se tratar de ficção em oposição a real ou verdadeiro. Inscrito na linhagem de Gaston Bachelard e de Gilbert Durand, no trabalho de compreensão do imaginário na construção da realidade, Maffesoli aponta um conjunto de características para construir essa noção.

O imaginário é parte de uma cultura e apresenta algo de imponderável e irracional. Funciona como uma matriz, uma espécie de energia, de sensibilidade de caráter coletivo. Trata-se de um "estado de espírito" coletivo que cimenta a vida social. O imaginário não é uma instituição, mas uma sensibilidade subjetiva coletiva (cf. MAFFESOLI, 2001, p. 75-80). 
Quanto ao mito, que povoa o imaginário, relembremos Barthes, que escreveu Mitologias entre 1954 e 19565, refletindo sobre alguns dos mitos da vida cotidiana francesa que se materializavam em sua atualidade (artigos, fotografias, filmes, exposições, brinquedos, astrologia...). Tomava-os, de início, conforme o sentimento que inspiravam: uma linguagem plena de "falsas evidências" (BARTHES, 2001, p. 7) - o que remete à relação aparência/essência-, que ele tentou fragmentar e interpretar, apelando para seu extenso conhecimento em literatura e ciências sociais.

O mito, diz ele, é uma fala, mas há um modo específico de produzir mitos. Uma árvore é naturalmente uma árvore, porém o uso social dela a transfigura de muitos modos: "é a história que transforma o real em discurso, é ela e só ela que comanda a vida e a morte da linguagem mítica. [...] o mito [...] não poderia de modo algum surgir da 'natureza' das coisas" (BARTHES, 2001, p. 132). Há, então, uma mensagem, mas a fala mítica tem a particularidade de ser "formada por uma matéria já trabalhada em vista de uma comunicação apropriada” (BARTHES, 2001, p. 132), pressupondo uma consciência significante.

Barthes trata o mito segundo a Semiologia, preconizada por Ferdinand de Saussure, e ainda não plenamente constituída à época em que ele estudava os mitos "modernos" (década de 1950) - o que não tira o mérito das análises que ele desenvolveu, que refletem uma semântica discursiva aparelhada das ciências sociais, "ciências dos valores". A semiologia, explica Barthes, trata das formas, estudando as significações independentemente de conteúdo. A Análise de Discurso, aliás, campo formado posteriormente a essa formulação de Barthes, também não propõe uma análise de conteúdo, mas uma semântica discursiva. É o que Orlandi (2001, p. 22) chama "ilusão de conteúdo", redução do sentido a um conteúdo, produzindo efeito ideológico de evidência (aparência). E a mitologia, diz Barthes, não escapa à ideologia.

Todo sistema semiológico presumiria três termos diferentes, em sua correlação: significante, significado, signo. O mito seria "um sistema particular, visto que ele se constrói a partir de uma cadeia semiológica que existe já antes dele: é um sistema semiológico segundo" (BARTHES, 2001, p. 136, grifo no original). Assim, uma totalidade sígnica se torna significante de novo signo, formando o mito.

O mito, como sistema segundo, é uma metalinguagem, em que o sistema básico é a linguagem-objeto de que se fala. Essa diferença de níveis remete ao tradicional par denotativo/ conotativo, que em Barthes se resolve como sistema linguístico/sistema mítico, este como ampliação daquele, em que o já signo se esvazia para atuar como significante em nova camada, resultando em novo signo - agora com caráter mítico.

\footnotetext{
${ }^{5}$ Em nota final redigida em 1970, Barthes esclarece que, tendo ressurgido, pelo movimento de maio de 1968 na França, a necessidade de uma crítica ideológica, a análise semiológica, bem como a teoria que experimentava em Mitologias, desenvolveram-se muito e tomaram novos caminhos; permaneceu, contudo, seu papel de instrumento de análise fina e de denúncia. O que utilizamos desse material (reavaliado de certo modo), relembrando movimentos específicos, é o que julgamos ainda pertinente para o tratamento discursivo aqui objetivado.
} 
Interessa-nos rever o caráter do mito especificado por Barthes no início: uma linguagem plena de falsas evidências - figurando como Bondade, Caridade, Humanidade, Pátria, Religião, Humildade etc. - categorias que parecem aderir ao real, falando por si. Elas reaparecem em Barthes deste modo: "o mito não esconde nada: tem como função deformar, não fazer desaparecer" (2001, p. 143, grifo no original). Esta é a percepção que ele tem do que Harari expõe como criação cultural de ficções, capazes de fazer convergir grupos e comunidades amplas e se pôr sob a liderança de outrem - sem, contudo, estabelecer juízo de valor ou apresentar essas ficções em confronto. Na caracterização de imaginário, por Maffesoli, também não há essa contraposição: o imaginário não é de direita nem de esquerda: ele atravessa todo o vivido.

Contudo, Barthes especifica adiante: “O mito não esconde nada e nada ostenta também: deforma; o mito não é nem uma mentira nem uma confissão: é uma inflexão" (BARTHES, 2001, p. 150). Ele chega, então, à noção de naturalização do conceito (do mito), finalizando com seu princípio de funcionamento: "transforma a história em natureza" (BARTHES, 2001, p. 150). Desse modo, aos olhos de quem consome mitos, o apelo que lhe é dirigido "pode ficar manifesto sem, no entanto, parecer interessado: a causa que faz com que a fala mítica seja proferida é perfeitamente explícita, mas é imediatamente petrificada numa natureza" (BARTHES, 2001, p. 150). Ou seja, "o mito é uma fala excessivamente justificada." (BARTHES, 2001, p. 151, grifo no original). Isso leva a que, rotineiramente, ele seja interpretado como um sistema fatual. Por isso, Barthes (2001, p. 153) o interpreta como "roubo de linguagem", ou "roubo por colonização" dos sentidos da língua. Nesse processo, finalmente, "a função do mito é transformar uma intenção histórica em natureza, uma contingência em eternidade” (BARTHES, 2001, p. 162-163). Em suma, naturalização do vivido, do histórico, da própria memória das comunidades em direção a uma forma única para o real: o mundo "sai do mito como um quadro harmonioso de essências" (BARTHES, 2001, p. 163). Daí que Barthes sintetize o mito como uma fala despolitizada-política entendida como "conjunto das relações humanas na sua estrutura real, social, no seu poder de construção do mundo" (BARTHES, 2001, p. 163). Entendemos que não se trata, estritamente, de discurso político, mas do político do discurso, do vivido social.

Uma fala política, não mítica, em contrapartida, seria uma fala direta, não metalinguística, em função das coisas mesmas, não de imagens (símbolos) construídas das coisas; seria a linguagem do homem produtor, aquele que transforma o real, sem apelar a uma imagem dele (BARTHES, 2001, p. 166). Uma linguagem tipicamente revolucionária, diz Barthes, não pode ser mítica: ela tenta produzir um mundo por seus atos e falas.

Temos, contudo, mitos de esquerda e mitos de direita. Um mito de esquerda, para Barthes, apodera-se de apenas alguns objetos e noções políticas, escapando-lhe o conjunto da vida social: é um mito pobre, artificial, que parece resumir-se em slogans - isto, como efeito de sua relação imediata com minorias oprimidas, proletárias ou colonizadas, cuja fala, embora real, é também restrita. Se de direita, é uma categoria essencial, que se projeta em todas as 
instâncias da vida social: da vida doméstica ao governo central. O opressor "tem a posse exclusiva da metalinguagem" (BARTHES, 2001, p. 169).

Termos-chave desta síntese teórica apontam para o modo possível de ajustar a concepção de Barthes a parâmetros de análise discursiva, sem destruir meramente o resultado daquele trabalho. A construção de um signo de segundo nível (mítico), no esquema semiológico, remete à distinção teórica que Orlandi (2009) propõe entre interpretação e compreensão: a ideologia produz a imagem de evidências do dizer já estabelecidas, naturalizadas, como resultado do imaginário, produzindo identificações esvaziadas de história - lugar do mito em Barthes, lugar da despolitização, porque se estaria transformando o historicismo da linguagem em natureza. Contudo, na interpretação, um enunciado já está impregnado de mitos, questão de leitura desavisada; não há uma linguagem ingênua - o signo primeiro no esquema de Barthes; a linguagem é opaca desde sempre; o analista precisa usar um dispositivo teórico para chegar à compreensão desse funcionamento, deslocando sua subjetividade para produzir outra leitura (em profundidade), que permita chegar ao processo histórico de produção do discurso (efeitos).

\section{(RE)CONSTRUINDO UM MITO}

Expostas as noções teóricas básicas, passamos a focalizar enunciados do Programa de governo selecionado, com respaldo de noções adicionais para a análise.

O Plano de Governo é um enunciado político, uma previsão de futuro, que distingue um candidato de outro. Sabendo-se que um deles teria o comando do "destino" de nossa nação, é importante analisar os possíveis efeitos de materialização de seu plano buscando antever um futuro político, econômico e social por meio dos enunciados apresentados-compromisso de cumprimento do que foi registrado.

Para os antigos gregos, antever o futuro era privilégio de Tirésias. Triste figura, cego por vingança divina, Tirésias recebeu de Zeus o dom da profecia para compensar-lhe a escuridão do presente. Os romanos atribuíam à deusa Fortuna, filha de Júpiter, a roda na qual o destino humano ia sendo decidido por seu capricho (BERNSTEIN, 1997, p. 15).

Em uma democracia contemporânea, contudo, não é tão evidente que crenças religiosas ou mitos mundanos possam mudar significativamente o rumo dos conflitos. Há sempre uma aposta, ainda que a ideia de destino não esteja cancelada.

Retomando a relação aparência/essência adotada aqui, buscamos analisar algumas propostas expostas pelo (então) candidato Jair Messias Bolsonaro em seu Plano de Governo ${ }^{6}$. O

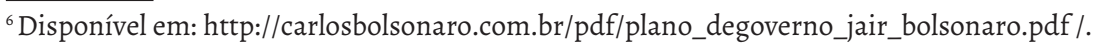


Plano intitula-se "O caminho da prosperidade, o Brasil que planejamos para o futuro", compondo-se de 81 lâminas no formato de slides do PowerPoint.

Assumido como Valores e Compromissos, elenca temas centrais assim rotulados: liberdade e fraternidade; direitos e deveres; imprensa livre e independente; a nossa bandeira éverde-amarela; mais Brasil, menos Brasília, entre outros. Em cada subtema, encontram-se outros enunciados que mostram, segundo sua visão, as verdades e o que é certo (como fará no futuro) e as mentiras e o que está errado (como é agora), visando cooptar adeptos que lhe confiariam o cargo de Presidente do Brasil, o que de fato ocorreu.

Para mostrar uma aparência que silenciaria a essência dos enunciados (a historicidade do discurso), observamos os efeitos de escolhas e de silenciamentos perceptíveis nas faltas ou nos excessos mostrados nestes enunciados que, propositais ou não, parecem encobrir informações e modulações relevantes que poderiam ou deveriam ali ser contempladas. Orlandi (2012), em entrevista à Globo Universidade, salienta que, no processo de interpretação, nos deixamos levar pelas evidências já construídas, com as quais nos relacionamos imaginariamente; a compreensão é que nos leva à historicidade, pelo conhecimento dos processos de produção.

Orlandi (2001, p. 128) explica que há ao menos duas formas de produção de efeitos de silêncio: a) o silêncio fundador, que produz as próprias condições para significar; b) a politica do silêncio, com duas modalidades: o silêncio constitutivo - ao enunciar algo, outras possibilidades são apagadas; e o silêncio local, ou censura - o "apagamento de sentidos possíveis, mas proibidos”. E complementa: "O silêncio é discurso. [...] fazendo significar de seu modo particular a interpretação” (ORLANDI, 2001, p. 128).

O lema de campanha é: "Brasil acima de tudo. Deus acima de todos". Se Deus está acima de todos, teria um porta-voz ou emissário. Como o cargo-mor da nação é o de presidente, no caso de eleição (como houve), o candidato exerceria domínio sobre todos como porta-voz de Deus.

Sendo Jair Messias Bolsonaro o nome do candidato, isso já o alinha a esta hipótese: a designação Messias traz uma carga semântica significativa, além de remeter a um redentor enviado por Deus à humanidade, estabelecendo uma nova ordem social. Quem, senão o próprio Messias, estaria autorizado a apresentar-se como salvador da pátria?

Visto que em nosso mundo necessitamos de "crenças em comum", dois ápices aparecem no enunciado-lema: Brasil e Deus. São criações subjetivas, mas muito fortes e presentes em quase todos os ideais dos brasileiros. Motes de senso comum como "Tudo posso Naquele que me governa", "Se Deus está conosco, quem estaria contra?" ratificam que existe um "ente" que nos protege. Isto vale para o Brasil. "Sou brasileiro com muito orgulho", "Deus é brasileiro", etc., também fazem acreditar que o ente "Brasil” está nos guiando.

Entende-se, então, que, juntando estes dois Entes num mesmo enunciado e aliando-o ao nome do candidato que traz Jair (iluminado de Deus) e Messias (redentor), cria-se um cenário 
indicativo de que há boas chances de sujeitos eleitores serem tocados por esta "mensagem". Como relata Paveau (2013, p. 96): "A construção da memória coletiva e [...] da memória discursiva está [...] fundamentalmente inscrita no desenvolvimento da história”. Isto é o que estamos tomando como a aparência do enunciado.

Apoiadores dessa forma de governar deslizam para a devoção religiosa, aguardando por um líder que os salve ou que os conduza através de uma jornada, emulando um poder quase doutrinário.

O cristianismo é a única religião a se organizar como uma Igreja. E como tal, postula o princípio de que certos indivíduos podem, por sua qualidade religiosa, servir a outros não como príncipes, magistrados, profetas, adivinhos, benfeitores, mas como pastores. Contudo, esta palavra designa uma forma muito específica de poder. (FOUCAULT, 1995, p. 237)

A respeito desta possível devoção, Foucault (1995, p. 237) acrescenta: "De certa forma, podemos considerar o Estado como a matriz moderna da individualização ou nova forma do poder pastoral", ressalvando que, neste caso, a ideia de salvação não remete ao mundo do além, embora possa se aproximar dele em certas instâncias.

O Plano de Governo abre com uma evocação de João 8: 32: "E conhecereis a verdade, e a verdade vos libertará". O trecho escolhido diz respeito a contexto de conflito com os judeus, remetendo à não liberdade com referência a pecado; a voz é a de Jesus, reportada pelo evangelista. A segunda lâmina do Plano tem o título: "O Brasil livre". Livre de quê? Liberdade, em todo caso, é palavra-chave no conjunto da proposta, que, passo a passo, vai desdobrar seus sentidos, cercando o que é, finalmente, denominado "O problema" (que remete, por associação, ao pecado): o legado do Partido dos Trabalhadores (PT).

Na lâmina 15 - "O Brasil é maior que nossos problemas" - encontramos o seguinte enunciado:

1. O Brasil passará por uma rápida transformação cultural, onde a impunidade, a corrupção, o crime, a 'vantagem', a esperteza, deixarão de ser aceitos como parte de nossa identidade nacional, POIS NÃO MAIS ENCONTRARÃO GUARIDA NO GOVERNO.

Com respeito ao trecho "O Brasil passará por uma rápida transformação cultural", podemos entender que nosso país sofre de uma cultura doentia (subversiva, opressiva, perversa, intolerante?). Parece que precisaríamos apagar tudo e começar do zero. Porém, remete diretamente à pergunta que precisa ser feita: Quem fará esta rápida transformação? Há resposta quanto aos instrumentos para a "recuperação" do país: as leis, a Constituição, a serem respeitadas - porém, depois de sofrerem mudanças. Mesmo a Lei maior parece desajustada, incapaz de prover justiça. 
Entretanto, é sabido que nenhuma cultura muda repentinamente - salvo se submetida a um regime de opressão, não com base em carisma, autoridade, mito. A lâmina 32 indica a linha de ação: redução da maioridade penal, cancelamento de progressão de penas, criação de dispositivo de imunidade para policiais (exclusão de responsabilidade), reforço para a propriedade privada, redirecionamento da política de direitos humanos (haveria direitos em excesso). Todas remetem, de alguma forma, ao tratamento com base em uma divisão já discriminada: há os que seguem as leis e os que as burlam; os bons brasileiros e os maus. Simultaneamente, porém, há a bandeira de anúncio a mudanças na lei, para mais ou para menos.

Somos criadores e devotos de mitos (deuses, magos, santos, ídolos, governantes, marcas, etc.); a forma como nos são materializados influencia nossas decisões. Constituem nosso imaginário. Lembremos o filósofo neokantiano Ernst Cassirer, que estudou teorias sobre o aparecimento de mitos e formulou sua própria perspectiva: "A consciência teórica, prática e estética, o mundo da linguagem e do conhecimento, da arte, do direito e o da moral, as formas fundamentais da comunidade e do Estado, todas elas se encontram originariamente ligadas à consciência mítico-religiosa" (CASSIRER, 1972, p. 64).

Evocando a aparência da doutrinação ideológica como um mal (resultante da conduta de maus brasileiros) a combater e erradicar, mostra-se na lâmina 33 ("Defesa nacional-Garantia da Lei e da Ordem"):

2. dentre instituições, grupos, pessoas ou atividades, que tiveram sua imagem atacada pela doutrinação ideológica de esquerda, certamente as Forças Armadas do Brasil estão entre as que mais sofreram.

"Doutrinação ideológica de esquerda", aí, é praticamente construção redundante, visto que a doutrinação sempre remete à esquerda, e se emparelha com "barbárie", em oposição ao heroísmo, ao espírito guerreiro (das Forças Armadas).

Em Análise de Discurso entende-se que não existe sujeito sem ideologia. Neste sentido, Orlandi (2009, p. 46) mostra que este "é o trabalho da ideologia: produzir evidências, colocando o homem na relação imaginária com suas condições materiais de existência”. Toda manifestação discursiva estará associada a um valor ideológico. E é neste sentido que alguns o associam à resistência (sentido oposto) e o utilizam como argumento de defesa e ataque, acrescentando ao caráter ideológico o efeito de doutrinação. Veja-se ainda na lâmina 22 ("Linhas de ação"):

3. SAÚDE E EDUCAÇÃO: eficiência, gestão e respeito com a vida das pessoas. Melhorar a saúde e dar um salto de qualidade na educação com ênfase na infantil, básica e técnica, sem doutrinar.

E na 41 (“A Educação também deveria ser melhor com o valor que o Brasil já gasta!”):

4. Conteúdo e método de ensino precisam ser mudados. Mais matemática, ciências e português, SEM DOUTRINAÇÃO E SEXUALIZAÇÃO PRECOCE. 
Na 46 ("Gestão é importante, porém, conteúdo, forma e estratégia precisam mudar!") preconiza-se o expurgo da "ideologia de Paulo Freire", e acentua-se, em quadro com fundo vermelho:

5. Um dos maiores males atuais é a forte doutrinação.

Doutrina, em sua acepção original, não apresentava esse veio pejorativo que é efeito detectado em doutrinação (o campo jurídico fundamenta seu trabalho em doutrinas jurídicas); contudo, desliza para sinalizar injunções de caráter criminal, na crítica a grupos e partidos. É o mito da pureza da ordem natural, desvinculada da história, liberada de qualquer ideologia. Uma doutrina se combate com outra, não com uma não-doutrina, não-ideologia. Sempre haverá valores.

Em novembro de 1937, na instalação do Estado Novo (uma "democracia autoritária"), Getúlio Vargas fez distribuir o Catecismo Cívico do Brasil Novo (BRASIL, 1937), livreto com perguntas e respostas relativas a vários âmbitos, aos quais se sobrepõe a nacionalidade e o patriotismo. Tratava-se de uma remissão à ancestralidade religiosa, embora a sujeição à religião se tivesse transformado progressivamente, a partir do século XVI, em sujeição ao Estado - bem marcada desde o século XVIII -, vingando a noção de responsabilidade individual, com o imperativo de amor à Pátria e dever ao Estado (cf. HAROCHE, 1992) - o que é visível nesse catecismo (catequese política). É também essa doutrina que se apresenta no Plano.

Tornaram-se modismos expressões como ideologia de esquerda, de direita, capitalista, socialista, feminista; mas o caráter ideológico não cabe, seletivamente, a quem é contrário à lei e à ordem, como parecem sugerir algumas expressões. Como expressa Orlandi (2009, p. 46), ideologia "é a condição para a constituição do sujeito e dos sentidos"; e ainda: "a ideologia não é ocultação, mas função da relação necessária entre linguagem e mundo". É ilusório associar o erro de um adversário à sua ideologia e crer na solução milagrosa do problema com base em sua "não-ideologia". No âmago deste confronto, pode-se estar silenciando, na essência, o jogo de poder projetando-se como desejo que, para obter satisfação, impõe o silenciamento ou exclusão do outro.

Uma relação de poder [...] se articula sobre dois elementos que lhe são indispensáveis por ser exatamente uma relação de poder: que "o outro" (aquele sobre o qual ela se exerce) seja inteiramente reconhecido e mantido até o fim como o sujeito de ação; e que se abra, diante da relação de poder, todo um campo de respostas, reações, efeitos, invenções possíveis (FOUCAULT, 1995, p. 243).

Outro enunciado que se mostra como um campo de efeitos de sentido está materializado na lâmina 35: "Sufocar a corrupção". 
6. Como pilar deste compromisso, iremos resgatar As Dez Medidas Contra a Corrupção, proposta[s] pelo Ministério Público Federal e apoiadas por milhões de brasileiros, e encaminhá-las para aprovação no Congresso Nacional. (negrito no original)

Este resgatar remete ao sentido de recuperar. O pacote de medidas foi retido no Senado, sem solução previsível. Quem teria sustado seu encaminhamento? Os de ideologias contrárias à do candidato? Aspecto relevante é o fato de serem dez as medidas. Seriam exatamente dez as necessárias e suficientes?

O número dez (10) aparece em muitos textos, alegorias e mitos no percurso da história, tal como os Dez Mandamentos; dez é também a base numérica mais utilizada no mundo. A utilização de dez medidas não se inscreve por acaso: está carregada semanticamente com sentidos ligados ao além, ao divino, ao mito. Se fossem oito ou treze talvez a percepção pela sociedade não tivesse o mesmo efeito. Na aparência, então, o enunciado materializa dez medidas contra a corrupção; em essência, pode trazer à tona sentimentos que remetem aos desígnios de um ser místico e libertador, que pune os ímpios e liberta os oprimidos.

Outra expressão-chave no movimento material do Plano tem como núcleo ou atributo populismo/populista. Na lâmina 5 ("Liberdade e fraternidade") encontramos:

7. Mais importante: uma Nação fraterna e humana, com menos excluídos, é mais forte. Há menos espaço para populistas e suas mentiras. O Brasil precisa se libertar dos corruptos. $\mathrm{O}$ povo brasileiro precisa ser livre de VERDADE!

Uma "Nação fraterna e humana”, neste caso, depende de uma exclusão de princípio: dos populistas, que são vinculados à corrupção e mentira. É uma contradição interna no contexto do Plano. Essa visão se repete nas lâminas 13 e 52, criando um muro entre dois tipos de população: "nós brasileiros" e os "populistas" (que são corruptos e mentirosos). Não se trata de estabelecer uma previsão global de como os princípios da democracia liberal serão controlados, mas de expurgo anunciado de quem se amoldar, pelo olhar de outrem, a essa definição. O que, na aparência, é uma boa nova, uma promessa de salvação, pode se resolver como uma divisão política que instiga a revolta e a divisão interna.

Lâmina 13 ("Liberalismo econômico"):

8. Corruptos e populistas nos legaram um déficit primário elevado, uma situação fiscal explosiva, com baixo crescimento e elevado desemprego.

Lâmina 52 ("Economia: garantir estabilidade macroeconômica”)

9. Para alcançar esses grandes objetivos sociais, nós brasileiros devemos afastar o populismo e garantir que o descontrole das contas públicas nunca seja ameaça ao bem-estar da população. 
Dado que populismo/populista já está estabelecido, qualificado e atribuído a um grupo, cuja exclusão se preconiza, cabe trabalhar a noção. Utilizamos um trabalho recente de Patrick Charaudeau, analista que tem privilegiado o caráter político do discurso, e que focaliza essa expressão.

Charaudeau (2018), constatando que em várias áreas o populismo é olhado como discurso a denunciar, entende que o olhar deve voltar-se à compreensão e sem atitude a priori. E pergunta-se: O populismo é de direita ou de esquerda? É o que nos interessa com respeito ao Programa.

Populismo, povo e população têm a mesma matriz. No documento, povo tem cinco (5) registros, e população aparece onze (11) vezes, ora como registro estatístico, ora como registro de grupo (população civil), ora como forma genérica (povo). A forma populismo, no entanto, é significada negativamente: $\mathrm{o}$ antipovo? Se um governo tem, necessariamente, de atender aos interesses de uma população, qual o sentido desse deslocamento?

Historicamente falando, explica Charaudeau (2018, p. 12-13, tradução nossa):

[...] afrontam-se duas posições radicalmente opostas. A dos juristas e dos psicólogos neodarwinianos do século XIX, para quem o populismo é um nacionalismo desnaturado, que serve se antecâmara ao totalitarismo. A de analistas contemporâneos que estimam que o populismo faz parte do jogo democrático, e mesmo que ele é o sintoma de um abandono das classes populares [...].

Dessa dupla visão, o autor tira pontos em comum: a relação entre movimentos populares e sua recuperação em um discurso que se aproxima do povo; o fato de que o populismo agrega indivíduos com pensamento e interesses variados (heterogeneidade); e que o populismo é um problema para a democracia porque está nela inscrito e combatido. Desse modo, conclui que o discurso populista serve tão bem à extrema direita como à extrema esquerda, produzindo-se, na modernidade, uma reciclagem desses dois discursos. Ele o faz considerando três planos: o contrato e cenografia do discurso político, a opinião pública e os imaginários discursivos da direita e da esquerda.

Se o populismo é uma atitude política originada no próprio povo, por que seria malvisto e mesmo condenado, como é o caso aqui? O discurso político é, por definição, demagógico, diz Charaudeau: apela a estratégias de persuasão, esperando aderência da maioria da população para os projetos, nas democracias, em vista de adversários com o mesmo propósito. Nesse contrato de várias instâncias propõe-se um discurso com uma cenografia prevista: há alguma desordem social que vitimiza os cidadãos; há uma fonte da desordem a denunciar; e há uma solução para a promoção de um novo estado de ordem que beneficie a população; a solução se projeta de uma imagem de líder como o único ou o melhor possível para realizar o projeto proposto (cf. CHARAUDEAU, 2018, p. 14). 
Tais elementos são destacados no Plano: é nomeado "O caminho da prosperidade" (implicita problemas econômicos); propõe um governo "decente" (implicita falta de moralidade, ética) que torne o Brasil "livre" (implicita um país em crise, subjugado) da influência de movimentos de esquerda; o proponente explicita valores e compromissos - bem como imagens típicas de simbolização religiosa de fraternidade - que devem refletir sua personalidade. Por espelhamento, apresenta-se como a extrema direita do que condena. Essa imagem era e é atraente: "as figuras dos líderes dependem do que está ancorado nas mentalidades de cada povo" (CHARAUDEAU, 2018, p. 22, tradução nossa).

Opinião pública, por sua vez, é uma noção fluida; precisa-se imaginar como opiniões pessoais podem se resolver em opinião coletiva, que em última análise estaria mais marcada de paixões, também instáveis e sujeitas a manipulação.

O que mais pesa na compreensão do fenômeno do populismo, para Charaudeau, são os sistemas de crença que vão caracterizar posicionamentos de direita ou de esquerda. A partir daí ele estabelece duas matrizes ideológicas: a de Direita e a de Esquerda, as duas com variantes.

A de Direita perspectiva o mundo pela Natureza; a desigualdade seria consubstancial à natureza humana. Em consequência, "as relações que os homens mantêm entre si são relações de força, e mesmo de dominaçãa" (2018, p. 16, grifo no original). Com esse fundamento, os valores defendidos são: a família como grupo, e a tradição, sobressaindo-se a figura do patriarca (tutela e proteção); o trabalho, impondo a relação entre superiores e inferiores; a nação, que funda o corpo social-povo, com um patrimônio identitário - o que justifica que qualquer inimigo desses fundamentos e valores seja expurgado, esteja ele no interior da nação/país (e então deve ser excluído pela inclusão) ou venha do exterior (e então deve ser rechaçado, incluído pela exclusão). Nas palavras de Ricoeur (1995, p. 100), “[...] todo sistema que define uma inclusão define também exclusões". A tendência, como doutrina, é o conservantismo, o segregacionismo, o patriarcalismo (cf. CHARAUDEAU, 2018, p. 16).

A matriz ideológica de Esquerda se fundamenta na ideia de que o homem se impõe à natureza, e a noção de progresso faz avançar a igualdade entre os homens. A partir desta base há contraposição aos valores de direita: desmancha-se a hierarquia e prestigia-se a solidariedade social; às crenças religiosas se opõe a neutralidade do Estado (laicidade); ao princípio de comando se opõe o princípio da contestação, visando ao interesse geral (cf. 2018, p. 16-17).

O Plano em análise se enquadra na matriz ideológica da Direita, mas sua produção não podia eximir-se da estratégia populista de conquista de poder, ainda que a imputando ao adversário, associando-a negativamente à corrupção e mentira. A anexação de atributos negativos leva à aparência de que o populismo é o mal a ser excluído pelo povo, vitimizado pela esquerda populista, e que deve optar, agora, por um governo (supostamente) não populista (!?). A vitimização, ademais, sofreu reforço com o evento do atentado sofrido pelo próprio candidato durante um comício em setembro de 2018. 
Esse é o imaginário estimulado pela direita, que conseguiu cooptar boa parte do eleitorado, envolvendo indiferentemente grupos conservadores e grupos com valores mesclados: demonização de culpados, levando ao medo generalizado, e construção de uma imagem de Salvador (Messias), explicitamente explorada - estratégia apresentada por Charaudeau com esses termos (cf. 2018, p. 17). O populismo, de qualquer matriz ideológica, também apela para o uso de palavras genéricas acessíveis à população, funcionando como lemas simbolicamente marcados - forma de dar indício de que não se faz discriminação quanto a grupos: prosperidade, liberdade, sagrado, trabalho, família, verdade, mentira, direito, dever, corrupção, servidão, crime, crise. O que sintetiza a proposta é a remissão ao lema Ordem e progresso (de fundo positivista) incrustado na bandeira brasileira (Lâmina 10: "faremos uma aliança da ordem com o progresso"), associado à ilusão de mudança imediata. Lâmina 10: "2019 será o ano da mudança"; Lâmina 15: "O Brasil passará por uma rápida transformação cultural”.

Quaisquer planos de governo podem assinalar, repetir e defender os mesmos valores (em sua face de categorias evidentes - aparência), por exemplo: nacionalismo, austeridade econômica, identidade nacional, embora com propósitos e argumentos distintos, bem como consequências distintas, porém ambos tendo uma fonte única: o ressentimento, que subsume uma memória comprometida-essência.

\section{CoNSIDERAÇõES FINAIS}

Propusemos, neste estudo, pensar em aparência como aquilo que se apresenta em seu caráter inelutavelmente imaginário, no mundo físico e na cultura em geral: no político, no social em suas práticas. É o exteriorizado, o que se mostra visível; seria o correlato, nas manifestações em linguagem, do intradiscurso, sua forma de concatenação na conformação do imaginário, das ficções criadas. Já a essência - ou o fundamento, a base - seria a fluidez, oscilando entre consciente e inconsciente, reproduzindo formas parafrásticas e produzindo polissemia, tendo como fonte primária o interdiscurso, de caráter memorial, criando e apagando efeitos de sentido nas mais variadas formas de linguagem. A essência tem conformação profunda, densa, aquilo que seria uma quase verdade, que tangencia o real: o que flui, evanesce, desliza - a teorização.

Buscamos, neste trabalho, observar e compreender os efeitos de interpretação em enunciados materializados no Programa de Governo do hoje presidente da República, Jair Messias Bolsonaro. Trabalhamos com a ideia de que o mostrado como aparência em seu plano, propositalmente ou não, silencia, em nossa análise, ora enunciados subliminares, ora argumentos falaciosos ou desvios de objetivo, que seriam o que tratamos como a essência do que está ali enunciado.

Assumimos a ideia da criação do mito como aparência (em sua visibilidade de acontecimento) silenciando a historicidade do sujeito como essência, mas, ao mesmo tempo, entendendo, como mostra Cassirer, que as formas fundamentais da comunidade e do Estado estão, 
em sua origem, ligadas à consciência mítico-religiosa. Ou seja, toda a cultura está enlaçada a essa ancestralidade, marcada por uma cicatriz indelével. Seja no cristianismo evangélico, seja no esquerdismo secular (os dois polos visíveis de uma linha heterogênea), trata-se sempre, como lembra Eliade (1996, p. 6), de "soteriologias, doutrinas da salvação", explorando mitos e seus símbolos.

O discurso político, em sua especificidade, ao enaltecer ou diminuir dizeres com valores axiológicos, suportados por argumentos e narrativas mitológicas ou históricas, influencia nossas escolhas e decisões, estando nós conscientes disto ou não. E as aparências, menos ou mais escrutinadas por nós, influenciam nos sufrágios. Mitos e seus rituais justificam comportamentos.

Em sua relação com os arquétipos mitológicos da memória, é perceptível também que, no discurso político, o passado se redesenha e há projeção para o futuro com alguns traços utópicos: um futuro que não comportará as mazelas do presente, como é preconizado nas promessas manifestadas no Plano - para não dizer profecias.

Considerando o exame de alguns pontos marcantes do Plano, percebemos que remete a um posicionamento politicamente ambíguo, mas atraente pelo caráter que apresenta, com tratamento mítico, de liderança capaz de salvar a Pátria, com apelo sintetizado no lema ali rememorado: Ordem e progresso. Possibilidade: Se houver ordem (com certos meios), haverá progresso (futuridade). Promessa ou profecia: Haverá ordem, portanto, haverá progresso.

Façamos, para finalizar, rápida referência à escolha da expressão no subtítulo do trabalho: A espada de Dâmocles. Quem almeja o poder deve pensar no preço a pagar. Todo líder deve saber que, dia após dia, haverá uma espada acima de sua cabeça.

\section{REFERÊNCIAS}

BARTHES, R. (1957). Mitologias. Tradução: Rita Buongermino e Pedro de Souza. 11. ed. Rio de Janeiro: Bertrand Brasil, 2001.

BERNSTEIN, P. L. Desafio aos deuses: a fascinante história do risco. Tradução: Ivo Korylowski. 23. ed. Rio de janeiro: Elsevier, 1997.

BIBLIA do Evangelismo contendo o Velho e o Novo Testamento. Tradução: João Ferreira de Almeida. São Caetano do Sul: Editora Bíblica, 2008.

BRASIL. Catecismo cívico do Brasil Novo. Rio de Janeiro: D. N. P., 1937.

CASSIRER, E. (1925). Linguagem e mito. São Paulo: Perspectiva, 1972.

CHARAUDEAU, P. Du discours politique au discours populiste. Le populisme est-il de droite ou de gauche? Policromias, Rio de Janeiro, v. 3, n. 1, p. 11-23, jun. 2018. 
ELIADE, M. (1952). Imagens e símbolos: ensaio sobre o simbolismo mágico-religioso. Tradução: Sonia Cristina Tamer. Prefácio Georges Dumézil. São Paulo: Martins Fontes, 1996.

FOUCAULT, M. O sujeito e o poder. In: RABINOW, P. DREYFUS, H. Michel Foucault. Uma trajetória filosófica. Tradução: Vera Porto Carrero. Rio de Janeiro: Forense Universitária, 1995. p. 231-249.

HALBWACHS, M. A memória coletiva. Tradução: Laurent Léon Schaffter. São Paulo: Editora Revista dos Tribunais Ltda., 1990 [1950].

HARARI, Y. N. Sapiens: Uma breve história da humanidade. Tradução: Janaína Marcoantonio. 30. ed. Porto Alegre (RS): L\&M, 2017.

HAROCHE, C. (1984). Análise crítica dos fundamentos da forma sujeito (de direito) (por uma análise das formas de estruturação da subjetividade pela religião e pelo direito). In: HAROCHE, C. Fazer dizer, querer dizer. Tradução: Eni P. Orlandi. São Paulo: Hucitec, 1992. p. 155-211.

KLEINMAN, P. Tudo o que você precisa saber sobre filosofia: de Platão e Sócrates até ética e metafísica, o livro essencial sobre o pensamento humano. Tradução: Cristina Sant'Anna. São Paulo: Editora Gente, 2014.

LACAN, J. O Seminário - Livro 3. As psicoses (1955-1956). Tradução: Aluísio Menezes. 2. ed. Rio de Janeiro: Zahar Editores, 1988 [1981].

MAFFESOLI, M. O imaginário é uma realidade. Entrevista concedida a Juremir Machado da Silva. Revista Famecos, Porto Alegre, n. 15, p. 74-82, ago. 2001.

NASCENTES, A. Dicionário etimológico da língua portuguesa. Prefácio de W. Meyer Lübke. Rio de Janeiro: Livraria Acadêmica, 1955.

ORLANDI, E. P. Discurso e texto: formulação e circulação dos sentidos. Campinas, SP: Editora Pontes, 2001.

ORLANDI, E. P. O inteligível, o interpretável e o compreensível. In: ORLANDI, E. P. Discurso e leitura. 8. ed. São Paulo: Cortez Editora, 2008. p. 101-119.

ORLANDI, E. P. Análise de discurso: princípios e procedimentos. 8. ed. Campinas, SP: Pontes, 2009.

ORLANDI, E. P. Entrevista concedida à Globo Universidade. São Paulo, 5 nov. 2012.

PAVEAU, M.-A. Os pré-discursos: sentido, memória, cognição. Tradução: Greciely Costa e Débora Massmann. Campinas: Pontes, 2013.

PÊCHEUX, M. (1983). Papel da memória. In: ACHARD, P. et al. Papel da memória. Campinas (SP): Pontes, 1999. p. 49-57. 
PÊCHEUX, M. Lecture et mémoire: projet de recherche (1983). In: MALDIDIER, D. L'inquiétude du discours. Textes de Michel Pêcheux choisis et présentés par Denise Maldidier. Paris: Editions des Cendres, 1990. p. 286-293.

RICOEUR, P. Leituras 1: Em torno ao político. Tradução: Marcelo Perine. São Paulo: Edições Loyola, 1995.

Recebido para publicação em: 12 maio 2020. Aceito para publicação em: 8 abr. 2021. 